\title{
Employment-Related Salaries and Benefits in Social Work: A Workforce Survey
}

\author{
Suk-Young Kang \\ Judy Krysik
}

\begin{abstract}
The purpose of this study was to develop a descriptive benchmark of social work employment in Arizona and to provide useful information to administrators, job seekers, and prospective social work students. The results, based on telephone and Internet surveys to a random sample of 463 NASW Arizona members, indicate that salary was positively related to level of education and years of social work employment experience. Salary was also higher for men than for women and higher for social workers with administrative roles compared to other roles. Access to employee-related benefits appeared widespread. Implications are provided for administration and future research.
\end{abstract}

Key Words: NASW, social work, salary, work related benefits, workforce survey

\section{INTRODUCTION}

Recently, the NASW warned the public of an impending shortage of professional social workers that could threaten the future of social work services for all Americans (Nadelhaft \& Rene, 2006). This warning came as no surprise. The National Institute on Aging (1987) had predicted a shortage of professionally educated social workers over three decades ago. In part, the shortage of professional social workers is due to a greater demand for social work services prompted by demographic changes in the United States. The NASW estimated a 35\% increase in employment opportunities for social workers due to the growing elderly population (Fritschi, 2001). The Bureau of Labor Statistics (2008) recently projected higher than average job growth for social workers to the year 2016, particularly in the fields of aging and health, and in rural areas. Child welfare agencies across the nation are also struggling to attract and retain professional social workers (Mor Barak, Levin, Nissly, \& Lane, 2006).

The Center for Workforce Studies, established by the NASW in 2004, was created to respond to the problem of limited knowledge on the social work workforce and thus inform related policy and advocacy efforts. The NASW workforce initiative was spearheaded by a national survey of licensed social workers in 2004. The 2004 NASW workforce survey indicated that shortages of professional social workers were burdening the existing workforce as well as disadvantaging the recipients of social work services. The survey documented "increases in paperwork, severity of client problems, caseload size, waiting lists for services, assignment of non-social work tasks, and level of oversight” (Whitaker, Weismiller, \& Clark, 2006, p. 5). The survey found commensurate

Suk-Young Kang, Ph.D., is an Assistant Professor in the School of Social Work at the University of Texas at Arlington and Judy Krysik, Ph.D., is an Associate Professor in the School of Social Work at Arizona State University. The authors express their appreciation to Ms. Carol Stambaugh, Executive Director, NASW Arizona; Dr. Mary Rogers Gillmore, Director, ASU School of Social Work; Ms. Jennifer Soltis, BSW Research Intern; and the 24 ASU MSW student volunteers who assisted with the survey.

Copyright (C) 2010 Advances in Social Work Vol. 11 No. 1 (Spring 2010), 82-94 
decreases in "job security, staffing levels (for both social worker and other staff), availability of supervision, and level of reimbursement for services" (Whitaker et al., p. 5). About one in five of the licensed social workers surveyed indicated, "vacancies in social work positions are common" and "difficult to fill” (Whitaker et al., p. 18).

Salary is one factor influencing recruitment and retention of professional social workers. The 2004 NASW workforce survey found the perceived importance of salary to be consistent across race, ethnicity, and gender (NASW The Center for Workforce Studies, 2006a; b; c; d; e). Approximately three-quarters of female and male licensed social workers indicated salary as the most important factor that would influence a job change (NASW The Center for Workforce Studies, 2006d; e).

The 2004 NASW survey found considerable variability in the salaries and wages of licensed social workers. The median salary for social work employees in 2004 was $\$ 55,129$ (Whitaker et al., 2006). Salaries varied significantly by gender, with males earning more than females; and by region, with metropolitan and Pacific regions experiencing higher salaries than south central and rural regions (Whitaker et al.). Sector of employment was also related to salary, with social workers in private practice reporting the highest salaries and those in private, nonprofit organizations reporting the lowest salaries (Whitaker et al.). Education and employment experience was positively correlated with salary (Whitaker et al.).

The purpose of this paper is to report the findings of a 2007 NASW Arizona Chapter workforce survey. The NASW Arizona survey was modeled after the 2004 NASW national survey. The 2004 national survey recruited very few subjects from Arizona ( $\mathrm{n}=$ 24), and therefore did not provide state-level information (NASW The Center for Workforce Studies, 2006f). The findings of this study, however, generally mirror those of the larger survey with 24 participants. For example, $72 \%$ of the social work respondents in Arizona were 45 years or older which is similar to the larger survey. However, without the current study's corroboration, the findings of the national study with only 24 social work respondents from Arizona cannot make a valuable contribution.

This paper describes social work salaries and benefits in Arizona as they relate to workforce demographics. This information can be used to compare across states and to examine within state trends. The study details a successful methodological approach that could be adopted by other NASW state chapters interested in carrying out similar studies without funding. This study addresses the need to replicate the national study in states that had low representation in the national study of licensed social workers. For 20 states, the sample size was less than 50 respondents. Among these 20 states, the sample size in three states was in the single digits (i.e., $n=5$ in Montana, $n=7$ in Rhode Island, $n=6$ in Wyoming) (NASW The Center for Workforce Studies, 2006g). The methods used in this study can be used to replicate the study in these 20 states.

\section{METHODS}

The present study was made possible by collaboration among the Executive Director of the NASW Arizona Chapter, the authors, 24 Arizona State University MSW student volunteers from two sections of a graduate research methods course, and one BSW 
research intern. Together the collaborators designed an 18-item workforce survey. The survey's design and research protocol relied heavily on the 2004 NASW workforce survey, and the evidence-based survey research practices outlined by Dillman (2000). The Institutional Review Board at Arizona State University approved the research procedures for this study.

An initial random sample of 683 NASW members was drawn for the survey from the January 2007 NASW Arizona Chapter membership roster. The sample size was based on a population of 1,892 members, a desired confidence level of $95 \%$, and a confidence interval of \pm 3 percentage points. Of the 683 members originally sampled, 43 were unable to be contacted because they had moved out of state or did not have working telephone numbers or e-mail addresses. Of the 640 potential respondents, 465 completed the survey yielding a $72.6 \%$ response rate. Based on the randomly selected sample of 465 members, the results have a maximum margin of sampling error of \pm 3.95 percentage points. The response rate in this study is high compared to other workforce surveys reported in the literature (See for example Dixon, 2002/2003; Whitaker et al., 2006).

In order to maximize response rate and minimize cost and time, Internet and telephone survey methods were chosen. Both telephone and Internet administration cost less and consume less time than mailed or in-person surveys. It was assumed that most professional social workers had access to the Internet and e-mail, and would be reasonably motivated to respond to a request from the Executive Director of their local NASW Arizona Chapter. Surveys that could be completed via the Internet would reduce the resources needed for telephone interviewing. Telephone administration was made feasible by the volunteer labor of $24 \mathrm{MSW}$ students who were granted access to private offices with telephones in the ASU School of Social Work. The survey was conducted as a service/learning project in two sections of a graduate research course instructed by the authors.

Individuals in the sample who had e-mail addresses recorded in the membership database received pre-survey notice e-mails. Pre-survey notice postcards were mailed to those without available e-mail addresses. The pre-notice emails and postcards, sent from the Executive Director of NASW Arizona, described the survey's importance and requested the member's participation.

The survey was programmed for the Internet using the upgraded version of Survey Monkey, and then piloted with NASW Arizona board members and MSW student volunteers. Access to the Internet survey was made available through a link sent in a second email. The Internet survey was open for one month. An interview schedule was developed for the telephone interviews and was piloted with the MSW student volunteers. The authors trained MSW students in telephone interviewing skills. The 24 students' first telephone interviews were supervised by one of the authors or an experienced peer. Telephone calls were made to potential respondents from Monday through Friday in both day and evening hours, and were conducted over a period of one month.

Three follow-up e-mails, also from the Executive Director of NASW Arizona, were sent to non-respondents at one-week intervals. The upgraded version of Survey Monkey 
facilitated the tracking of non-response and permitted the automated generation of follow-up e-mails to non-respondents. Any individual not responding after three e-mail reminders was then transferred to the telephone list. To encourage participation, three gift cards valued from $\$ 50$ to $\$ 100$ each were offered as raffle prizes for respondents.

\section{Sample}

Of the 465 NASW Arizona members who responded to the survey, 258 (55.5\%) responded by Internet and 207 (44.5\%) were interviewed via telephone. Of the 175 nonrespondents, 32 refused participation and 143 non-respondents did not respond to numerous telephone calls or e-mails.

The sample demographics shown in Table 1 closely reflect the population of NASW Arizona members. For instance, $78.9 \%$ of the sample was female and $21.1 \%$ was male compared to the overall population of NASW Arizona members who were $81 \%$ female and $19 \%$ male. The racial and ethnic distribution of the sample also reflected the population, $85 \%$ and $86 \%$ white respectively. Finally, the majority of survey respondents were from Maricopa County, the largest urban county in Arizona (57.4\%), followed in frequency by Pima County, the second largest urban county (23.0\%) and $19.5 \%$ came from other areas of the state. The information in Table 1 indicates the sample's geographic distribution was highly representative of the overall population of NASW Arizona Chapter members. Population data on age were not available, however, in the sample, $40 \%$ of the respondents were at least 55 years of age, and $9 \%$ were age 65 or older.

Not only did the demographic characteristics of the sample mirror the population, but they also reflected licensed social workers responding to the national NASW workforce survey described earlier in this paper (NASW The Center for Workforce Studies, 2006f). That is, the sample could be described as predominantly white, female, nearing the standard age of retirement, and urban. 
Table 1. Comparison of Selected Demographic Characteristics

\begin{tabular}{lcc}
\hline Demographic Characteristics & $\begin{array}{c}\text { Sample } \\
(n=347)\end{array}$ & $\begin{array}{c}\text { Population } \\
(N=1,892)\end{array}$ \\
\hline Gender & & \\
female & $78.9 \%$ & $81.0 \%$ \\
male & $21.1 \%$ & $19.0 \%$ \\
Ethnicity & & \\
white & $85.1 \%$ & $86.4 \%$ \\
Hispanic & $5.3 \%$ & $5.5 \%$ \\
black/African American & $2.9 \%$ & $1.7 \%$ \\
Asian/Pacific Islander & $2.9 \%$ & $2.0 \%$ \\
Native American & $2.0 \%$ & $2.3 \%$ \\
Other & $1.8 \%$ & $59.4 \%$ \\
Region & & $22.7 \%$ \\
Maricopa County & $57.4 \%$ & $17.9 \%$ \\
Pima County & $23.0 \%$ & \\
All other areas & $19.5 \%$ & \\
Age & & \\
25 years or younger & $1.2 \%$ & \\
26 to 34 years & $12.0 \%$ & \\
35 to 44 years & $14.9 \%$ & \\
45 to 54 years & $32.4 \%$ & \\
55 to 64 years & $31.0 \%$ & \\
65 years or older & $8.5 \%$ & \\
\hline
\end{tabular}

Note. Demographic data were only collected for the 347 NASW Arizona members who were employed in social work at the time of the survey. Population data on ethnicity were missing for 572 of the 1,892 NASW Arizona Chapter members. Data on age were missing for five respondents

\section{RESULTS}

Of the 465 NASW Arizona members responding to the survey, 118 or approximately $25 \%$ were not employed in social work. Of those not employed in social work, 41 were employed in non-social work occupations (see Table 2). The remaining individuals, 77 of the 118, were not gainfully employed. Although the survey did not ask respondents about their reasons for non-employment, several offered explanations related to retirement, job seeking, and time out for personal health, further education, and caregiving. Those employed in non-social work positions often commented that they could not support themselves on the amount of money that they could earn in social work jobs. 
Table 2. $\quad$ Employment Status of NASW Survey Respondents

\begin{tabular}{lcc}
\hline Employment Status & $\begin{array}{c}\text { Frequency } \\
(N=465)\end{array}$ & Percent \\
\hline Employed in social work & 347 & $74.6 \%$ \\
Employed, other than social work & 41 & $8.8 \%$ \\
Not currently employed & 77 & $16.6 \%$ \\
Status of only those Employed in Social Work & $(n=347)$ & \\
year-round, full-time & 237 & $68.9 \%$ \\
year-round, part-time & 88 & $25.6 \%$ \\
less than 12 months, full-time & 13 & $3.8 \%$ \\
less than 12 months, part-time & 6 & $1.7 \%$ \\
\hline
\end{tabular}

Note. Data on status of only those employed in social work were missing for three respondents.

The next section of this paper focuses on the 347 respondents who were employed in social work. As shown in Table 2, of the 347 respondents, only $68.9 \%$ were employed year-round, full-time. A sizable proportion, $25.6 \%$, was employed year-round, part-time; $3.8 \%$ were employed full-time although less than 12 months per year, such as a ninemonth academic position; and 1.7\% were employed both part-time and fewer than 12 months per year. The majority of the 347 respondents who were employed in social work, $81 \%$, reported employment with a single employer; and 19\% reported employment with two or more employers.

\section{Social Worker Employment Experience}

The majority of the 347 respondents, $54 \%$, had been employed as social workers for more than 16 years. Relatively few respondents were newcomers to social work. For instance, only $2.0 \%$ of the social work employed subgroup had been social workers for less than one year, and $13.3 \%$ had between one and five years of experience in the profession (See Table 3). Almost 38\% of employed social workers had between one and five years tenure with their current employers, and about $16 \%$ had less than one year. 
Table 3. Percent Distribution of Social Work Experience and Current Tenure

\begin{tabular}{lcc}
\hline $\begin{array}{l}\text { Duration of } \\
\text { Employment }\end{array}$ & $\begin{array}{c}\text { As a Social Worker } \\
(n=345)\end{array}$ & $\begin{array}{c}\text { With Current Employer } \\
(n=344)\end{array}$ \\
\hline Less than 1 year & $2.0 \%$ & $16.3 \%$ \\
1 to 5 years & $13.3 \%$ & $37.8 \%$ \\
6 to 10 years & $16.2 \%$ & $18.0 \%$ \\
11 to 15 years & $14.2 \%$ & $9.9 \%$ \\
16 or more years & $54.2 \%$ & $17.7 \%$ \\
\hline
\end{tabular}

\section{Characteristics of Social Work Employment}

The majority of the 347 respondents, $79 \%$, were employed by the private sector, split almost equally between for-profit (39\%), and non-profit (40\%) entities. In the public sector, social workers were employed in order of decreasing frequency by, local government (6.5\%), federal and state government (5\% each), postsecondary institutions $(3 \%)$, and the military (1\%). The majority of respondents described mental health as the main focus of their primary employment $(36.8 \%)$, followed in frequency by medical health (13.9\%), family services (8.9\%), child welfare (6.5\%), and hospice (5.6\%). Addictions, aging, and school social work were each represented as a primary focus of employment by $4.5 \%$ of respondents.

Of those employed in social work, $69 \%$ were in positions that required certification or licensure. About one-fourth, 23\%, reported experiencing employment-related safety issues, and $33.8 \%$ were reportedly required to work weekends or shift work. Ability to speak Spanish, or a language other than English was required in $16 \%$ of the social work positions, and $25 \%$ of the respondents working in social work were in positions that required work in rural locations.

\section{Social Work Salaries and Wages}

Table 4 presents the percentage distribution of annual gross wages or salary for the 235 year-round, full-time social workers and the 105 part-time and part-year employed social workers. Less than $10 \%$ of full-time, full-year employed social workers had salaries lower than $\$ 35,000$. About $53 \%$ of full-time employed social workers earned between $\$ 35,000$ and $\$ 59,999$, and almost 38\% reported earnings of $\$ 60,000$ or more. 
Table 4. Percentage Distribution of Annual Gross Wages or Salary from Social Work

\begin{tabular}{lcc}
\hline Annual Gross Wages or Salary & Full-time $(n=235)$ & Part-time $(n=105)$ \\
\hline Less than $\$ 15,000$ & $0.4 \%$ & $19.0 \%$ \\
$\$ 15,000-\$ 19,999$ & $0.4 \%$ & $11.4 \%$ \\
$\$ 20,000-\$ 24,999$ & - & $6.7 \%$ \\
$\$ 25,000-\$ 29,999$ & $2.6 \%$ & $10.5 \%$ \\
$\$ 30,000-\$ 34,999$ & $6.0 \%$ & $5.7 \%$ \\
$\$ 35,000-\$ 39,999$ & $10.6 \%$ & $12.4 \%$ \\
$\$ 40,000-\$ 49,999$ & $20.0 \%$ & $11.4 \%$ \\
$\$ 50,000-\$ 59,999$ & $22.6 \%$ & $13.3 \%$ \\
$\$ 60,000-\$ 69,999$ & $12.8 \%$ & $3.8 \%$ \\
$\$ 70,000-\$ 79,999$ & $7.7 \%$ & $1.9 \%$ \\
$\$ 80,000-\$ 99,999$ & $10.6 \%$ & $2.9 \%$ \\
$\$ 100,000+$ & $6.4 \%$ & $1.0 \%$ \\
\hline
\end{tabular}

Note. Part-time includes those working less than 12-months per year, full-time.

Income from all social work employment was examined by sector of primary employment for the 235 social workers with year-round, full-time employment. The sectors of employment, considered by highest to lowest salaries or wages, are ranked thus: (1) university/college/military; (2) local government; (3) private, for-profit, including private practice; (4) federal government; (5) private, non-profit; and (6) state government. Social workers employed full-time and year-round with administrative roles earned significantly more than social workers employed solely in direct service roles, including case management, $t(216)=3.75, p=.0002$ (two-tailed), and counseling or psychotherapy roles $t(299)=4.30, p<.0001$ (two-tailed). Licensure and area of residence, i.e., rural compared to urban, did not have a statistically significant impact on earnings from full-time, year-round social work employment. Education was significantly related to salary as expected, however, the correlation was weak $(r(342)=.15, p=.004)$. This weak correlation is likely due to the over representation of masters educated social workers among the NASW membership. Most of the respondents, $90 \%$ held a masters degree as their highest level of education, about $5 \%$ had achieved a bachelors degree and $5 \%$ a doctorate, thus there was little variation in education. Years of social work employment experience and salary were also significantly related. The relationship between experience and income could be characterized as moderately positive $(r(235)=$ $.46, p .<.0001)$. 


\section{Access to Employment-Related Benefits}

Table 5 displays comparative information on access to 12 employment-related benefits for full-time, full-year employed social workers and part-time or part-year employed social workers. As expected, access to employment-related benefits was greater for full-time, full-year employed social workers than for part-time or part-year employees. The exception was flexible work hours, available to about two-thirds of all employed social workers in the sample. Although the availability of employment-related benefits appears widespread, the survey did not take into account whether or not the employees took advantage of workplace benefits, or the associated costs of such benefits. The majority of social workers in this study had relatively long durations of employment. Emphasizing the duration of employment and access to employer-sponsored health insurance and other benefits may be a good way to recruit individuals into the social work profession.

Table 5. Percent of Social Workers Reporting Access to Employment-Related Benefits

\begin{tabular}{lcc}
\hline Type of Benefit & $\begin{array}{c}\text { Full-time } \\
(n=235)\end{array}$ & $\begin{array}{c}\text { Part-time } \\
(n=105)\end{array}$ \\
\hline Health insurance & $85.8 \%$ & $57.8 \%$ \\
Dental insurance & $80.2 \%$ & $44.7 \%$ \\
Life insurance & $77.1 \%$ & $42.6 \%$ \\
Pension & $75.1 \%$ & $49.5 \%$ \\
Tuition reimbursement & $58.7 \%$ & $30.5 \%$ \\
Travel reimbursement & $69.2 \%$ & $47.4 \%$ \\
Dependent child or medical savings account & $53.1 \%$ & $30.9 \%$ \\
Cell phone/cell phone reimbursement & $51.2 \%$ & $25.0 \%$ \\
Continuing education reimbursement & $67.6 \%$ & $39.6 \%$ \\
Paid association membership & $27.5 \%$ & $11.0 \%$ \\
Flexible work hours & $66.7 \%$ & $63.7 \%$ \\
Paid family leave & $52.7 \%$ & $28.3 \%$ \\
\hline
\end{tabular}

Note. Part-time includes those working full-time and less than 12-months per year. The percentages represent lower-bound estimates, as some respondents did not know if their employers offered access to specified benefits. 


\section{DISCUSSION}

The 2007 NASW Arizona workforce survey is the product of a successful collaboration between the leadership of the Chapter, and faculty and students from the Arizona State University School of Social Work. The high response rate to the survey, $72.6 \%$, and the comparability of the sample to the population serve to illustrate the power of random sampling combined with evidence-based survey research practices. Concentrated in metropolitan areas, the sample was consistent with the NASW Arizona membership, and mirrored the population in terms of race, ethnicity, and gender. Thus, the findings are generalizable and accurate within plus or minus 3.95 percentage points.

The findings of this study suggest possible strategies for recruitment, and point to the benefits of the profession for those who may be considering social work. These include long duration of employment and access to employment related benefits. Our findings suggest the need to plan for the retirement of social workers from the baby boom generation. The findings also point out the need to address the retention of social workers prior to retirement.

The survey found that one-quarter of those sampled were not employed in social work at the time of the survey, and about 35\% of those were employed, but outside of social work. Future research should examine the loss of this sizable subgroup from the social work profession to determine reasons for leaving social work and whether those leaving are different demographically from those remaining in the profession. The data collected from the current survey cannot answer whether or not those who leave social work are rewarded through higher salaries and greater benefits, and how much income factored into their decision to leave. This is an important area of inquiry for future workforce research. If we are concerned about the shortage of professional social workers, this study would suggest that we begin with a focus on ensuring those that we are producing are being retained in social work. This gap in knowledge might be filled by alumni studies that survey recent cohorts of graduates.

Another sizable subgroup of NASW Arizona members, 23\% of the total sample, was employed less than full-time, year-round. The current survey found that regardless of whether respondents were employed full-time or part-time in social work, about twothirds had flexible work schedules. The issue of keeping the balance between work and life is a critical issue in many workplaces including social work (Shoenfeld, 2005). Previous studies have found that flexibility in the workplace, such as flextime and a compressed workweek, had a positive effect on productivity/performance, job satisfaction, absenteeism, and satisfaction with work schedule (Baltes, Briggs, Huff, Wright, \& Neuman, 1999) and was associated with self-rated physical health (Swanberg \& Simmons, 2008). The flexibility associated with many social work positions, including the availability of part-time employment, make social work a particularly attractive career choice, especially for those who desire or require a greater balance in employment and personal life. This may also help explain why NASW members tend to be predominantly female and older. This finding has important implications for the interpretation of workforce data on salaries. Promoting the profession of social work to potential students should highlight salary and benefits, and the opportunity for flexible work schedules. 
This survey's findings leave questions as to whether or not social workers are losing ground in regard to earnings. Income from full-time, year-round social work employment in 2007 appeared consistent with that reported in the 2004 NASW workforce survey. In 2004, 45\% of licensed full-time social workers in Arizona $(n=24)$ reportedly earned between $\$ 40,000$ and \$59,000 annually, and 23\% earned between \$20,000 and \$39,000 annually (NASW The Center for Workforce Studies, 2006f). The current 2007 NASW Arizona survey found $19 \%$ of social workers with annual gross earnings from full-time social work in the range of $\$ 20,000$ to $\$ 39,000$, and $42.6 \%$ with full-time earnings between $\$ 40,000$ and $\$ 59,000$ annually, \pm 3.95 percentage points. Comparing the results of these two surveys seem to indicate that professional social workers have not made salary or wage gains over the past three years. In order to better describe trends in social work salary and wages in Arizona, replicating the current workforce survey in coming years is critical. Future research in this area should test the assumptions that salaries and benefits are the main inducements in the social work hiring process. Many social work students are drawn to the profession by their commitments to society. Further study may need to focus on employee morale and working conditions.

The access to employer-provided benefits documented in this survey makes social work appear attractive, with over $85 \%$ of full-time social workers reporting access to employer-sponsored health insurance. Combined with information on projected workforce shortages within the profession, this information can be used to market social work as a career choice in Arizona. Future social work workforce surveys, however, should collect data on employee-perceived adequacy of workplace benefits, as well as the take-up rates and employee cost of specified benefits. Not only will this allow the assessment of trends over time, but will add a further dimension to our current understanding of workplace benefits for social workers.

Unknown is how many professional social workers in Arizona are members of the state NASW chapter. As this study was restricted to NASW Arizona members, it has limited ability to describe the entire professional social work workforce. Available information indicates that the NASW Arizona membership is heavily biased in terms of graduate degree holders and licensed social workers making the current survey limited in its ability to assess the benefits of additional education beyond the bachelor's-level and the potential benefits of licensure.

Further study should be conducted to explore the effects of the recent economic crisis. Retention of social workers from burn-out is also a critical issue. Based on this study, 31\% of the sample was between 55 to 64 years, younger than the retirement age for Social Security benefits. It would be useful to know if their plans for retirement have changed since the data were collected given the economic downturn. 


\section{References}

Baltes, B. B., Brigges, T. E., Huff, J. W., Wright, J. A., \& Neuman, G. A. (1999). Flexible and compressed workweek schedules: A meta-analysis of their effects on work-related criteria. Journal of Applied Psychology, 84(4), 496-513.

Bureau of Labor Statistics, U.S. Department of Labor. (2008). Occupational Outlook Handbook, 2006-07 Edition, Social Workers, Retrieved February 29, 2008, from http://www.bls.gov/oco/ocos060.htm

Dillman, D. A. (2000). Mail and Internet surveys: The tailored design method ( $2^{\text {nd }}$ ed.). New York: Wiley.

Dixon, R. (Dec 2002/Jan 2003). Spring 2002 salary survey results. Social Work Networker (NASW IL Chapter magazine), XLI, 1-5.

Fritschi, L. P. (2001, September). Gerontological social workers needed. Aging (The newsletter of the NASW section on Aging), 3(3), 1-14. Washington, DC: NASW.

Mor Barak, M. E., Levin, A., Nissly, J. A., \& Lane, C. J. (2006). Why do they leave? Modeling child welfare workers' turnover intentions. Children and Youth Services Review, 2(5), 548-577.

Nadelhaft, A., \& Rene, D. (2006, March). Landmark study warns of impending labor force shortages for social work profession. Washington, DC: National Association of Social Workers. Retrieved March 18, 2008 from http://www.socialworkers.org/pressroom/2006/030806.asp

NASW The Center for Workforce Studies. (2006a). 2004 National study of licensed social workers demographic fact sheet - Hispanic/Latino social workers.

Washington, DC: Author. Retrieved July 18, 2007, from http://workforce.socialworkers.org/studies/demo_fact_hispanic.asp

NASW The Center for Workforce Studies. (2006b). 2004 National study of licensed social workers demographic fact sheet - Non-Hispanic, white social workers. Washington, DC: Author. Retrieved July 18, 2007, from http://workforce.socialworkers.org/studies/demo_fact_caucasian.asp

NASW The Center for Workforce Studies. (2006c). 2004 National study of licensed social workers demographic fact sheet - Black/African American social workers. Washington, DC: Author. Retrieved July 18, 2007, from http://workforce.socialworkers.org/studies/demo_fact_africanamerican.asp

NASW The Center for Workforce Studies. (2006d). 2004 National study of licensed social workers demographic fact sheet - Female social workers. Washington, DC: Author. Retrieved July 18, 2007, from http://workforce.socialworkers.org/studies/demo_fact_female.asp

NASW The Center for Workforce Studies. (2006e). 2004 National study of licensed social workers demographic fact sheet - Male social workers. Washington, DC: 
Author. Retrieved July 18, 2007, from

http://workforce.socialworkers.org/studies/demo fact male.asp

NASW The Center for Workforce Studies. (2006f). 2004 National study of licensed social workers - quick facts - Arizona. Washington, DC: Author. Retrieved July 18, 2007, from http://workforce.socialworkers.org/states/Arizona.pdf

NASW The Center for Workforce Studies. (2006g). 2004 National study of licensed social workers - quick facts - by state. Washington, DC: Author. Retrieved April 6, 2010, from http://workforce.socialworkers.org/studies/demo_area.asp

National Institute on Aging. (1987). Personnel for health needs of the elderly through the year 2020. Bethesda, MD: Department of Health and Human Services, Public Health Service.

Schoenfeld, G. (2005). Work-life balance: An MBA alumni report. The Graduate Management Admission Council (GMAC) Research Report. 1-12. Retrieved August 25, 2009, from www.gmac.com/NR/rdonlyres/.../RR0509_WorkLifeBalance.pdf

Swanberg, J. E., \& Simmons, L. A. (2008). Quality jobs in the new millennium: Incorporating flexible work options as a strategy to assist working families. Social Service Review, 82(1), 119-147.

Whitaker, T., Weismiller, T., \& Clark, E. (2006). Assuring the sufficiency of a frontline workforce: A national study of licensed social workers. Executive summary. Washington, DC: National Association of Social Workers.

\section{Author's note:}

Address correspondence to: Suk-Young Kang, Ph.D., Assistant Professor, University of Texas at Arlington School of Social Work, 211 S. Cooper Street, Arlington, TX 76019.

Email: suk-young.kang@uta.edu 